\title{
The moral logic of political violence
}

\author{
Jeremy Ginges \\ Department of Psychology \\ The New School for Social Research \\ 80 5th Avenue, New York, NY 10011, USA
}

Word count: 1499

Correspondence: gingesj@newschool.edu (J. Ginges)

Keywords: political psychology, war, cognition, culture, morality, rationality

Citation: Ginges, J. (2019). The Moral Logic Of Political Violence. Trends in Cognitive

Sciences, 23, 1-3. DOI: 10.1016/j.tics.2018.11.001

This preprint may not exactly replicate the final version published in the journal. It is not the copy of record

\begin{abstract}
There is a moral logic to reasoning about political violence. People will often fight not for individual or collective material gain, but because of their commitment to abstract moral and
\end{abstract}


sacred ideas. Moreover, decisions to support or oppose war are descriptively deontological, and are relatively insensitive to material costs or benefits. 
We need to better understand how people make decisions about going to war before we can hope to limit or prevent armed conflict. The general assumption in the social sciences and in the world of public policy has been that people will engage in political violence when they consider it to be the most effective way of reaching individual and collective material goals. However, recent research and theorizing [1-7] reveals that there is a moral logic to reasoning about political violence that leads people to act in defiance of self and collective material interests.

In the social and behavioral sciences, investigations of intergroup conflict and aggression often begin with the premise that violence is a result of instrumentally rational reasoning bounded by heuristics that influence economic decision-making [8]. Violent human conflict is generally depicted as being motivated by material grievances or opportunities where an individual's decision to be in favor of, or to participate in war is the outcome of (imperfect) cost-benefit assessments; that is, of instrumental rationality [9]. Here I present evidence that people may not reason instrumentally about political violence. This does not mean that political violence is expressive or reactive irrational behavior. Indeed, most political violence is purposeful, goal directed and thus rational behavior. I suggest that the literature provides evidence for two propositions. First, that people will be willing to kill and die more for their commitment to abstract ideas (or collective fictions) such as the nation or a system of government, than for the material interests of self or kin. Second, that people process decisions about war as deontological moral choices, leading to decisions that are strikingly insensitive to material consequences. 


\section{People kill and die for their commitment to abstract causes}

Economists and political scientists typically assume that people will take part in war only when it is in their material self interest to do so [9]. However, research with Jewish Israelis and Palestinians in the West Bank and Gaza shows that people more likely to engage in political violence are less motivated by personal achievement, or social status, than other actors, but more motivated by values such as tradition and conformity [10]. This is because people's concept of "self" includes more than just the individual organism, or even close kin. Although we live in a material world, humans are often motivated to act in the name of abstract ideas such as the nation, "holy land", or a desired system of government [11]. These abstract ideas can become so important that they fuse with an individual's sense of self, such that threats to these ideas may be processed as existential threats to self [12].

To take one instance, people often feel viscerally fused with identity groups like the nation. "Identity fusion" has been shown to be a good predictor of willingness to sacrifice all for the said collective, and to engage in political violence. A field study of Libyan revolutionaries found that combatants are more likely than non-combatants to report being more fused with their battalion than their family [6], indicating that willingness to sacrifice the primary family unit may be a feature of combatants.

We can extend the concept of identity fusion to abstract ideas other than identity group. Indeed, in some cases commitment to other abstract ideas can trump commitment to groups in motivating violence. For example, much political violence is carried out to defend what I and others have termed "sacred values" - things people regard as having no economic price and 
therefore being non-fungible with material goods [11]. In fieldwork I have done with Jewish Israeli settlers in the West Bank, interviewees commonly say that their commitment to the sacred value of eretz israel (the land of Israel) is more important than the existence or future of the state. Likewise, in field experiments in Iraq frontline fighters tended to say that their commitment to sacred values (like "kurdisheity" for Kurdish fighters) trumped commitment to identity groups they reported being fused with (such as nation or family). In contrast, non-combatant Spanish civilians generally chose a group over a value [4].

A central feature of instrumental rationality is that commitment to end goals as well as means to achieve such goals should be sensitive to cost-benefit calculations. However in intergroup disputes involving sacred values, people may adopt the use of violence in defiance of material consequences; and once people decide that violence is morally mandated their commitment to such violence is strikingly insensitive to consequences.

\section{Commitment to sacred values in defiance of self and collective material interests}

When sacred values clash in intergroup disputes, attempts to prevent violence with material incentives can backfire [10,11]. For example, in one set of experiments carried out with Israelis and Palestinians in the West Bank and Gaza, participants were randomly presented with one of two compromises over a disputed issue such as Jerusalem: a straight compromise for peace, or the same compromise for peace plus a material incentive such as the promise of a life free of violence, or billions of dollars to the collective. When participants were moral absolutists with respect to the issues in conflict (regarding them as sacred values) adding a material incentive backfired, ironically increasing support for violent opposition to the deal. The 
existence of culturally specific sacred values does not itself impede tolerant interactions across

cultures (see Box 1). However, aggression may occur when one group acts to demean or threaten the second group's sacred values.

\section{Decisions about war are relatively insensitive to consequences}

Rather than being a product of a breakdown in morality, war is often regarded as a moral necessity if not a moral good $[2,7,13]$. While moral reasoning is important to collective action in general [5], people tend to make decisions about war in a deontological way such that violence is either seen as prohibited or mandated. This leads to decisions that are relatively insensitive to material consequences. In anonymous surveys of Jewish Israelis living in the West Bank and Gaza, participation in non-violent protest (aggressive and non-aggressive) was related to both the perceived effectiveness of such behavior and its perceived "righteousness". However, participation in violent attacks was predicted by "righteousness" and unrelated to effectiveness $[3]$.

Cross-cultural experiments show similar effects [2]. In one experimental paradigm participants were randomly assigned to consider their support for either a non-violent (negotiation) or violent response (armed attack) to the kidnapping and imminent murder of 100 innocent civilians. In prior tests, participants thought both options were equally appropriate and desirable. However, when asked to indicate how many hostages they required to be rescued to support the response they were considering, participants in the negotiation condition demanded between 80-100 hostages to be rescued, while those in the armed attack condition option required only 1 hostage to be rescued. Participants in the military conditions would often give 
strategic reasons for their responses, typically by arguing that violence will deter future attacks. Yet a subsequent experiment showed that support for military options was similarly insensitive to its deterrent capability [2]. Thus people reason differently about violent and non violent option in intergroup conflicts, using the logic of instrumental rationality for non-violence, but deontological reasoning when making choices about political violence. This can lead to systematic inconsistency of preferences for military action (see Box 2).

\section{Conclusion and future directions}

If decisions about violence are processed as deontological moral choices, when is violence seen as mandated? This is a question that demands future research with the answer likely varying across culture and context. In general we might hypothesize that violence is mandated by a sense of existential threat, produced by a belief that the other group hates and desires to destroy the in-group [14] or by threats to values that are processed as having existential importance.

In this paper I suggest that warfare is often motivated by commitments to abstract ideas, or sacred values, that come under threat. In these situations, people show a willingness to trade the material security (or existence) of themselves and their kin for such values. I also propose that decisions about war are the result of deontological, or value rational reasoning rather than instrumentally rational reasoning. It is of course possible that military and political leaders may have instrumentally rational reasons to favor violence. But we should not take assertions of instrumental rational processes at face value. In our experiments, even when people assert that they are making instrumentally rational choices, their actual decision making reveals a pattern of 
deontological reasoning [10]. While war is often said to be to be politics by other means, we reason differently about war than other means of achieving end goals, showing relative insensitivity to its material costs and benefits for the individual, or the collectives in whose name we fight.

BOX 1. Diversity of sacred values does not impede intergroup tolerance

Humans seem able to enjoy tolerant and cooperative relations with members of other groups who have different sacred values. In experiments in Lebanon (with Sunni, Shia and Christian Lebanese) and Morocco (with Arabs and Berbers), participants were asked to fill out questionnaires regarding the things in life they believed were moral issues, and do the same from the perspective of a typical member of another group. We then measured their openness to have close tolerant relations with members of the other group. Participants willingness to live close by, or have close social relations with, members of other ethnic or religious groups was strongly contingent on the belief that they share similar universal moral values such as do no harm, or reciprocate favors. But desired physical and social distance was unrelated to perceived differences in what we term parochial values - such as differing religious beliefs - likely because people realize and expect that such values differ across cultures [15].

BOX 2: Support for political violence is influenced by the framing of choices Instrumental rationality assumed people make stable and consistent choices. But because people tend to use deontological reasoning when evaluating military options, their choices about war can be relatively unstable. In one experiment a representative sample of Jewish Israelis were 
asked about their support for options to combat the perceived threat from the Iranian nuclear weapons program. Participants were randomly assigned to answer in a separate evaluation mode where they had to make choices about a diplomatic option (negotiation) or a military option (bombing campaign), or joint evaluation mode where they had to make a choice between bombing and negotiation. While support for diplomacy was relatively stable under both joint and evaluation modes (around 55\% in favor), support for military action was greater in the separate mode $(63.4 \%)$ than in joint mode $(45.6 \%)$. Because people are making utilitarian choices about diplomacy (is it the best thing to do?) other options such as military ones may be easily brought to mind in the separate evaluation mode. However, because people are making deontological choices about military action (is it right or wrong?), they likely do not easily consider other available options unless forced to in the joint evaluation mode. Thus, support for war over diplomacy may be exaggerated if the public (or policymakers) consider each of these options separately rather than jointly.

Acknowledgments: This work was supported by funding to the author from the NSF (SES 1559387), and the AFOSR ( FA9550-14-1-0030 DE). Thanks to E.A. Ginges, N. Rudich, M.

Pasek, J.F. Black, J. Smith, G. Tsudaka, H. Sheikh, and M.S. Rad.

1 Leidner, B. and Ginges, J. (2017) What You Ask Is What You Get: Citizens' Support for Military Action, But Not Diplomacy, Depends on Question Framing. Analyses of Social Issues and Public Policy 17, 184-204

2 Ginges, J. and Atran, S. (2011) War as a moral imperative (not just practical politics by other means). Proc. Biol. Sci. 278, 2930-2938 
3 Ginges, J. and Atran, S. (2009) What Motivates Participation in Violent Political Action. Ann. N. Y. Acad. Sci. 1167, 115-123

4 Gómez, Á. et al. (2017) The devoted actor's will to fight and the spiritual dimension of human conflict. Nature Human Behaviour 1, 673-679

5 Mooijman, M. et al. (2018) Moralization in social networks and the emergence of violence during protests. Nature Human Behaviour 2, 389-396

6 Whitehouse, H. (2018) Dying for the group: Towards a general theory of extreme self-sacrifice. Behav. Brain Sci. DOI: 10.1017/S0140525X18000249

$7 \quad$ Rai, T.S. et al. (2017) Dehumanization increases instrumental violence, but not moral violence. Proc. Natl. Acad. Sci. U. S. A. 114, 8511-8516

8 De Dreu, C.K.W. and Gross, J. Revisiting the Form and Function of Conflict: Neurobiological, Psychological and Cultural Mechanisms for Attack and Defense Within and Between Groups. Behav. Brain Sci. DOI: 10.1017/S0140525X18002170

9 Humphreys, M. and Weinstein, J.M. (2008) Who Fights? The Determinants of Participation in Civil War. Am. J. Pol. Sci. 52, 436-455

10 Ginges, J. et al. (2011) Psychology out of the laboratory: the challenge of violent extremism. Am. Psychol. 66, 507-519

11 Ginges, J. et al. (2007) Sacred bounds on rational resolution of violent political conflict. Proc. Natl. Acad. Sci. U. S. A. 104, 7357-7360

12 Varshney, A. (2003) Nationalism, Ethnic Conflict, and Rationality. Perspectives on Politics 1, 85-99

13 Fiske, A.P. and Rai, T.S. (2014) Virtuous Violence: Hurting and Killing to Create, Sustain, End, and Honor Social Relationships, Cambridge University Press.

14 Waytz, A. et al. (2014) Motive attribution asymmetry for love vs. hate drives intractable conflict. Proc. Natl. Acad. Sci. U. S. A. 111, 15687-15692

15 Obeid, N. et al. (2016) How Moral Perceptions Influence Intergroup Tolerance: Evidence from Lebanon, Morocco and the United States. Personality and Social Psychology Bulletin $43,381-391$ 